\title{
Design, Development and Performance Evaluation of the Manually Controlled Rotary Type Paddy Cutter with the Knapsack Sprayer Power Utilized
}

\author{
R. Ravindra Raju ${ }^{1 *}$, P. Shankar Prasad ${ }^{2}$ and V. Rayan Rao ${ }^{3}$
}

${ }^{1}$ Department of Applied Engineering, Vignan's Foundation for Science, Technology and Research University - Valdamud-522213, Guntur District, Andhra Pradesh, India

${ }^{2}$ Department of Irrigation and CAD (Agricultural Engineering) - Hyderabad-500022, Rangareddy District, Telangana, India

${ }^{3}$ Department of Farm power and Machinery, College of Agricultural Engineering and Technology- Bapatla-522101, Guntur District, Andhra Pradesh, India

*Corresponding author

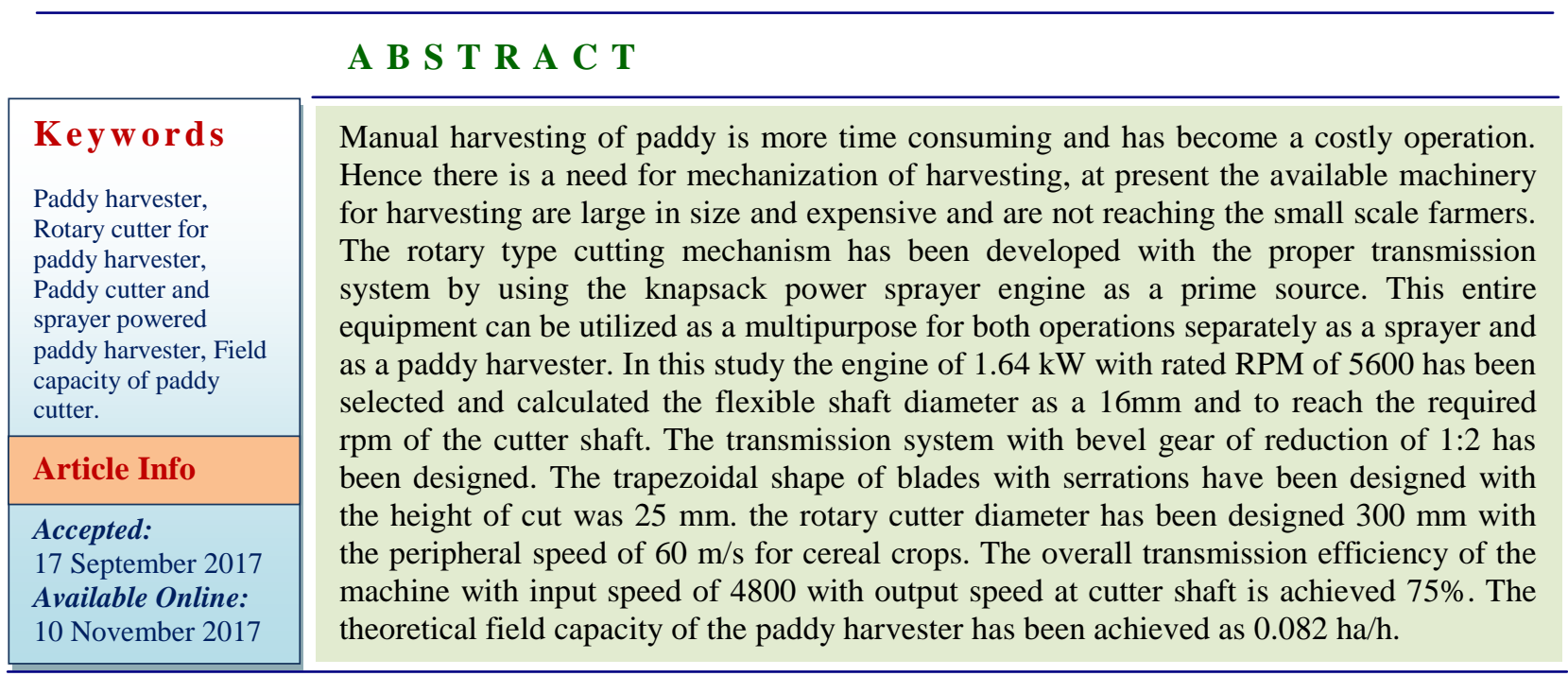

\section{Introduction}

Manual harvesting of paddy is more time consuming, and has been become a costly operation. Manual harvesting of paddy with local sickle takes 170 - 180 man-hours per hectare. Hence, there is a need for the mechanization of harvesting. At present the available machinery for harvesting are large in size and expensive, and are not within the reach of marginal farmers. The present day harvesters have two types of cutting mechanisms, one is of shear type reciprocating mechanism and other is of impact type rotary cutter.

The reciprocating cutter bar is commonly used for harvesting cereal crops and pulse crops. Rotary type disc cutter has more scope and potential in harvesting because they are simple and sturdy in construction. Due to the fewer moving parts in the rotary cutting system the design becomes more reliable and convenient to handle. Hence, there is a need 
to develop a rotary harvester, there by project on Design, Development and Performance Evaluation of the Manually Controlled Rotary type paddy cutter with the knapsack sprayer power utilized" has been taken up with the following objectives.

To design the rotary cutter for the paddy harvester.

To design the Transmission system for the Cutting system.

To test the overall efficiency of the machine.

To evaluates the field capacity of the machine.

\section{Materials and Methods}

The details of design of Manually Controlled Rotary type paddy cutter with the knapsack sprayer power utilized and the procedure for testing the speed transmission efficiency are below.

Design the rotary cutter for the paddy harvester consists of Details of power source.

Design of Cutting system and Design of Transmission system

\section{Details of power source}

The existed Honda engine has been taken as power source for operating the power operated and manually controlled paddy harvester.

The specifications of the power source have been shown in table 1 .

One end of the flexible shaft has been connected to the crankshaft $\mathrm{b}$ threading.

\section{Design of cutter assembly}

Majumdar et al., (1983) presented the kinematics of a single rotary blade harvesting machine.

The optimized equation has been presented as

$\mathrm{Vm} / \mathrm{Ve} \leq \mathrm{nh} / 2 \pi \mathrm{R}$

Where, $\mathrm{Vm}=$ Machine forward speed, $\mathrm{m} / \mathrm{s}$; $\mathrm{Ve}=$ Cutter peripheral velocity, $\mathrm{m} / \mathrm{s} ; \mathrm{n}=$ No. of teeth on the periphery of the disc; $h=$ Height of the teeth over the disc of the cutter, $\mathrm{m} ; \mathrm{R}=$ Radius of the cutter, $\mathrm{m}$

Machine forward speed which is the operator's average walking speed,

$\mathrm{Vm}=2.73 \mathrm{kmph}=0.76 \mathrm{~m} / \mathrm{s}($ Srinivas et al., 1996).

The peripheral velocity should be between 20 $\mathrm{m} / \mathrm{s}$ and $60 \mathrm{~m} / \mathrm{s}$ for cutting the cereal crops) Akritiids, 1974).

The speed of the cutter shaft $=3000$ RPM

We know, peripheral velocity of the cutter, $\mathrm{Ve}=\frac{\pi D N}{60} \leq 60 \mathrm{~m} / \mathrm{s}$

Where, $\mathrm{D}=$ Diameter of the Cutter; $\mathrm{N}=$ Speed of the cutter, 3000 RPM

To have the velocity of the cutter,

$20 \leq \frac{\pi D N}{60} \leq 60=0.13 \leq \mathrm{D} \leq 0.38$

Therefore diameter of the cutter bar should be between $0.13 \mathrm{~m}$ and $0.38 \mathrm{~m}$.

So an intermediate diameter of the cutter of $0.3 \mathrm{~m}$ has been taken. 
Now, the peripheral velocity of the cutter,

$\mathrm{Vc}=\frac{\pi x 0.3 x 3000}{60}=47.12 \mathrm{~m} / \mathrm{s}$

\section{Height of the teeth on the cutter (h)}

Height of the teeth has been taken as $2.5 \mathrm{~cm}$, to accommodate to cut the crop at least a single stubble at a time.

\section{No. of teeth on the periphery (n)}

This depends on the forward speed velocity and energy of cutting.

One revolution of cutter gives the energy $=$ Torque at the cutter $\mathrm{x}\left(2 \pi^{\mathrm{c}}\right)$

\section{Torque at the cutter}

Power produced by the engine at 4800 RPM

$=\frac{\text { RPM of the Engine }}{\text { Maximum RPM }} \mathrm{X}$ Rated Power

$=\frac{4800}{5600} \times 0.82=0.71 \mathrm{~kW}$

Power available at the cutter $=$ Power Produced by the engine $x$ Efficiency of the transmission system

$=0.70 \times 0.75=0.52 \mathrm{~kW}=520 \mathrm{~W}$

Torque at the cutter $=\frac{\text { Power }}{\text { Angular Velocity }}$

Angular velocity of the cutter shaft $=\frac{\pi \mathrm{DN}}{60}=$ $\frac{2 \pi \times 3000}{60}=314.15 \mathrm{rad} / \mathrm{s}$

Torque at the cutter $=\frac{520}{314.15}=1.66 \mathrm{~N}-\mathrm{m}=$ $0.17 \mathrm{~kg}-\mathrm{m}$

One revolution of the cutter gives the energy $=0.17 \times 2 \pi^{\mathrm{c}}=1.07 \mathrm{Kg}-\mathrm{m}$
For one revolution of the cutter the time taken in seconds $=\frac{60}{\text { RPM of the cutter }}$

$=\frac{60}{3000}=0.02 \mathrm{~s}$, in $0.02 \mathrm{~s}$, the machine moves a forward distance

$=($ Machine forward speed $) \times$ time

$=0.76 \times 0.02=0.015 \mathrm{~m}$ nearly $0.02 \mathrm{~m}$

\section{Area covered in $0.02 s$}

$=0.02 \mathrm{~m} \mathrm{x}$ (diameter of the cutter $)=0.02 \mathrm{x}$ $0.3=0.006 \mathrm{~m}^{2}$

No. of hills in $0.006 \mathrm{~m}^{2}$ area to be cut by the cutter

Consider a least spacing of $0.1 \mathrm{~m} \mathrm{x} 0.1 \mathrm{~m}$

Therefore No. of hills in $0.006 \mathrm{~m}^{2}=\frac{0.006}{0.1 \times 0.1}=$ $0.6=$ nearly 1 hill

Maximum transverse impact rupturing work of 1 single stem has been taken as $0.0508 \mathrm{Kg}$ $\mathrm{m}$

Considering a hill contains 12 stems

The energy required to rupture 1 hill $=0.0508$ x $12=0.61 \mathrm{Kg}-\mathrm{m}$

Hence it has been observed that the cutter has $=\frac{1.07-0.61}{1.07} \times 100=50 \%$ of excess energy

It has been considered that the $50 \%$ of energy can be utilized to accelerate the cutter and energy losses in bending while impact. Thus the cutter energy is sufficient.

So, no. of teeth. $\mathrm{n}$ required on the periphery can be found by the following equation 
$=\frac{\text { Forward movement of the machine in } 1 s}{\text { Height of the teeth on the cutter }}=\frac{0.02}{0.025}$

$=0.8=$ nearly 1 teeth

But to accommodate uniform energy utilization under closed cropping it has been selected 4 no. of teeth on the periphery.

Therefore No. of teeth on the periphery, $\mathrm{n}=4$

For verification of the design parameters of the cutter, kinematics equation of a cutter has been used.

$\frac{V m}{V c} \leq \frac{n h}{2 \pi R}$

$=\frac{0.76}{47.12} \leq \frac{4 \times 0.025}{2 \times \pi \times 0.15}=0.016 \leq 0.106$

The above relation says that underutilization of energy, but it is not true because it has been taken no. of teeth, $n=4$ instead of $n=1$, By substituting $\mathrm{n}=1$

Which gives

$\frac{V m}{V c} \leq \frac{n h}{2 \pi R}=\frac{0.76}{47.12} \leq \frac{1 X 0.025}{2 \times \pi \times 0.15}=0.016 \leq 0.026$ which has been satisfied the equation of the kinematics.

\section{Cutter shape}

An oblique angle of $25^{\circ}$ has been provided. A sharpening angel of $20^{\circ}$ has been provided based on the data given on the research data.

Serration are been given for efficient penetration on $3 \mathrm{~mm}$ hardened tool steel.

The cutter teeth have been fixed on a $3 \mathrm{~mm}$ MS sheet of $25 \mathrm{~cm}$ diameter.

The MS sheet has been fixed with bolts and nuts below a $1.5 \mathrm{~kg}$. MS disc of $12.5 \mathrm{~cm}$ which is attached to the cutter shaft with the help of welding.

\section{Transmission system}

Transmission consists of flexible Shaft

\section{Calculation of diameter of flexible shaft}

The shaft encounters only power operated and manually controlled paddy harvester twisting moments with suddenly applied load with a major shock.

Diameter of a flexible shaft has been found torsion equation by considering the solid mild steel shaft.

Torsion equation

$\frac{T}{J}=\frac{F s}{r}$

Where,

$\mathrm{T}=$ Torque acting on the shaft, $\mathrm{N}-\mathrm{m}$

$\mathrm{J}=$ Polar moment of inertia of the shaft about the axis of rotation, $\mathrm{m} 4$

Fs = Maximum Allowable shear stress in the material, $\mathrm{N} / \mathrm{m} 2$

$\mathrm{R}=$ Distance from the neutral axis to the outermost fibre $=\mathrm{d} / 2, \mathrm{~m}$

$\mathrm{D}=$ Diameter of the shaft

By substituting the, for $I=\frac{\pi d 4}{32}$ and Simplifying,

Torque acting on the shaft,

$\mathrm{T}=\frac{\pi \mathrm{xfs} \times \mathrm{ds}}{16}$

Totque, $\mathrm{T}$ can be found from the equation of power 
$\mathrm{P}=\frac{2 \pi \mathrm{NT}}{60}$

Where, $\mathrm{P}=$ Rated power of the power source, $\mathrm{W} ; \mathrm{N}=\mathrm{RPM}$ of the power source, RPM; T = Torque supplied by the power source, $\mathrm{N}-\mathrm{m}$

By taking the speed of the power source,

$\mathrm{N}=4800$ RPM; $\mathrm{P}=0.82 \mathrm{Kw}=820 \mathrm{~W}$

Substituting in equation (2)

$820=\frac{2 \times 3.142 \times 4800 \times \mathrm{T}}{60}$

$\mathrm{T}=1.63 \mathrm{~N}-\mathrm{m}=1630 \mathrm{~N}-\mathrm{m}$

By considering the factor for suddenly applied load with major shock, $\mathrm{Kt}=2.0$

Therefore the Equivalent torque, $\mathrm{Te}=\mathrm{Kt} \times \mathrm{T}$ $=2 \times 1630=3260 \mathrm{~N}-\mathrm{mm}$

Substituting the Equivalent torque in place of torque acting on the shaft in equation (1) and maximum allowable shear stress for the mild steel.

$\mathrm{Fs}=56 \mathrm{~N} / \mathrm{mm} 2$,

$3260=\pi \times 56 \times \mathrm{d}^{3} / 16$

$\mathrm{d}=6.67 \mathrm{~mm}$

Therefore the diameter of the shaft has been taken with the higher available diameter of $16 \mathrm{~mm}$. Other end of the flexible shaft is connected to the pinion shaft with a suitable coupling.

\section{Gear box}

Gear box has been provided for two purposes

To reduce rpm by 1.2 times. To change the axis of transmission horizontal to vertical.
One end of the pinion shaft has been attached with flexible shaft and other end has been fixed with pinion.

Gear shaft has been fixed vertically to the ground. One end of the gear shaft has been fixed with the gear to match with the pinion and other end has been for mounting the cutter.

\section{Testing of the overall transmission efficiency}

The RPM at the engine has been fixed and the flexible shaft of the assembled power operated and manually controlled paddy harvester has been attached to the crank shaft.

The RPM at the end of the gear box shaft and cutter shaft has been measured by different trials. The transmission efficiency has been calculated using the following equation.

Sped transmission efficiency $=\frac{\text { Output Speed }}{\text { Input Speed }} \mathrm{x}$ 100

$=\frac{N 2}{N 1} \times 100$

Where,

N1 = RPM of the Engine

$\mathrm{N} 2=\mathrm{RPM}$ at the end of the cutter shaft

\section{Results and Discussion}

Gear box has been tested for speed transmission efficiency and the reading has been noted in table 3. Speed transmission efficiency at different speeds has been calculated. A graph between input speed and transmission efficiency have been shown in above, it has been observed that the speed transmission efficiency varies between 90.5 to $91 \%$ for input speed variation from 3600 5600 (Fig. 1). 
Table.1 The specifications of the power source

\begin{tabular}{|l|l|}
\hline Rated power & $1.64 \mathrm{~kW}$ \\
\hline RPM & $3600-5600$ \\
\hline Weight & $5 \mathrm{~kg}$ \\
\hline
\end{tabular}

Table.2 Specifications of the gear box

\begin{tabular}{|l|l|}
\hline Type of Gears & Bevel Gears \\
\hline No.of Teeth & Pinion $=12$, Gear $=14$ \\
\hline Shafts & $\begin{array}{l}\text { Pinion shaft Diameter }=14 \mathrm{~mm} \\
\text { Gear shaft Diameter }=16 \mathrm{~mm}\end{array}$ \\
\hline Casing & Cast iron \\
\hline Lubrication & Grease \\
\hline Bearings & Ball Bearings \\
\hline
\end{tabular}

Table.3 Measurement of the RPM at the end of the gear shaft

\begin{tabular}{|l|l|l|l|l|l|l|l|l|l|}
\hline \multirow{2}{*}{ S.no } & \multicolumn{4}{|c|}{ Engine Speed, N $\mathbf{R P M}$} & \multicolumn{4}{c|}{ Engine Speed, $\mathbf{N}_{2}$ RPM } & \multirow{\eta}{*}{$\%=\frac{\mathbf{N 2}}{\mathbf{N 1}}$} \\
\cline { 2 - 10 } & Trial 1 & Trial 2 & Trial 3 & Mean & Trial 1 & Trial 2 & Trial 3 & Mean & X 100 \\
\hline 1 & 5420 & 5510 & 5505 & 5478 & 4900 & 4936 & 5020 & 4984 & 91.2 \\
\hline 2 & 5290 & 5320 & 5390 & 5333 & 4850 & 4920 & 4925 & 4847 & 90.9 \\
\hline 3 & 4890 & 4789 & 4796 & 4825 & 4150 & 4270 & 4500 & 4381 & 90.8 \\
\hline 4 & 4510 & 4210 & 4110 & 4276 & 3950 & 4020 & 4095 & 3878 & 90.7 \\
\hline 5 & 4120 & 3900 & 4020 & 4013 & 3730 & 3850 & 3945 & 3635 & 90.6 \\
\hline 6 & 3620 & 3611 & 3609 & 3613 & 3330 & 3420 & 3485 & 3269 & 90.5 \\
\hline
\end{tabular}

Table.4 Measurement of the RPM at the end of the cutter shaft

\begin{tabular}{|c|c|c|c|c|c|c|c|c|c|}
\hline \multirow[t]{2}{*}{ S.no } & \multicolumn{4}{|c|}{ Engine Speed, $\mathrm{N}_{1}$ RPM } & \multicolumn{4}{|c|}{ Engine Speed, $\mathrm{N}_{2} \mathrm{RPM}$} & \multirow{2}{*}{$\begin{array}{l}\eta \%=\frac{N 2}{N 1} \\
X 100\end{array}$} \\
\hline & Trial 1 & Trial 2 & Trial 3 & Mean & Trial 1 & Trial 2 & Trial 3 & Mean & \\
\hline 1 & 5560 & 5540 & 5550 & 5550 & 4200 & 4202 & 4184 & 4195 & 74.9 \\
\hline 2 & 5220 & 5210 & 5210 & 5210 & 3920 & 900 & 3880 & 3900 & 74.8 \\
\hline 3 & 4810 & 4610 & 4870 & 4830 & 3600 & 5550 & 3480 & 3543 & 73.5 \\
\hline 4 & 4470 & 4380 & 4820 & 4436 & 3240 & 3220 & 3180 & 3200 & 72.1 \\
\hline 5 & 4230 & 3920 & 4040 & 4070 & 3020 & 2900 & 2830 & 2915 & 71.8 \\
\hline 6 & 3600 & 3650 & 3640 & 3626 & $\begin{array}{l}\text { Over } \\
\text { load }\end{array}$ & $\begin{array}{l}\text { Over } \\
\text { load }\end{array}$ & $\begin{array}{l}\text { Over } \\
\text { load }\end{array}$ & $\begin{array}{l}\text { Over } \\
\text { load }\end{array}$ & \\
\hline
\end{tabular}




\section{Specifications of the power operated manually controlled paddy harvester}

\begin{tabular}{|l|l|}
\hline Power source & $\begin{array}{l}\text { Knapsack mist blower engine, 0.82kW Two } \\
\text { stroke petrol engine 3600 }-5600 \mathrm{rpm}\end{array}$ \\
\hline Transmission System & $\begin{array}{l}\text { Flexible shaft } 16 \mathrm{~mm} \text { diameter and } 2 \mathrm{~m} \text { length. } \\
\text { And gear box with bevel gears. }\end{array}$ \\
\hline Height of cut & $10 \mathrm{~cm}$ \\
\hline Diameter of cutter & $30 \mathrm{~cm}$ \\
\hline Design RPM of cutter & $3000 \mathrm{RPM}$ \\
\hline Blade shape & Trapezoidal serrated \\
\hline Design forward speed of the machine & $2.73 \mathrm{kmph}$ \\
\hline
\end{tabular}

Fig.1 Variations of speed and overall speed transmission efficiency of gear shaft of the machine assembly with respect to engine speed

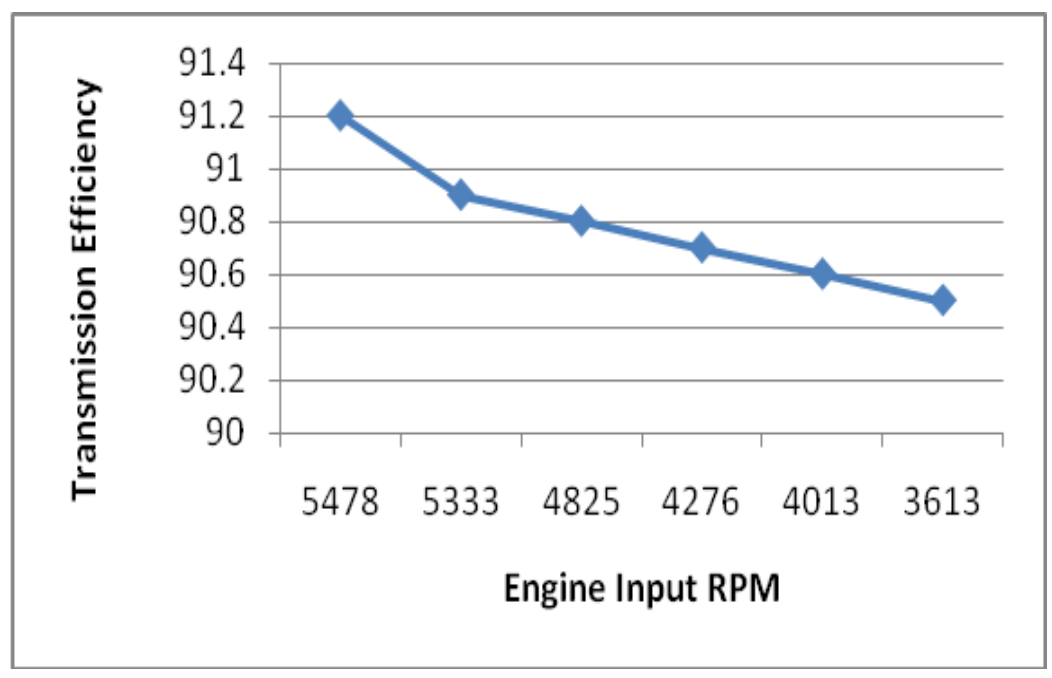

Fig.2 Variations of speed and overall speed transmission efficiency of cutter shaft of the machine assembly with respect to Engine speed

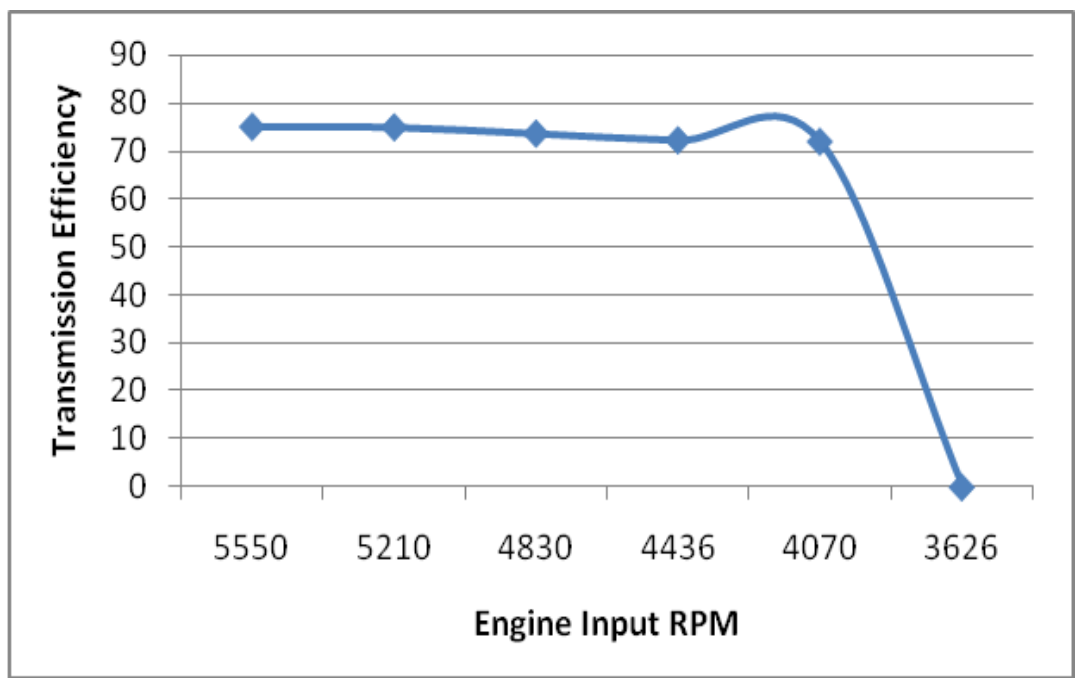


Power operated and manually controlled paddy harvester has been tested for the speed transmission efficiency and readings have been noted in table 4. Speed transmission efficiency at different speeds has been calculated.

A graph between input speed and transmission efficiency have been shown in figure 2 , it has been observed that the speed transmission efficiency varies between 71.8 74.9 for the input speed variations from 4000 $-5600 \mathrm{rpm}$.

The machine has been automatically stopped due to the load coming on to the engine.

\section{Field capacity of the machine}

Field capacity $=\frac{\text { Area Covered , ha }}{\text { Time taken to cover the area }}$

Take area covered $=1$ hectare

Forward speed of the machine $=2.73 \mathrm{kmph}$ (Design speed)

$=2.73 \times 1000 / 3600=0.76 \mathrm{~m} / \mathrm{s}$

Width of cut $=0.3 \mathrm{~m}$

Distance to be moved by the machine to cover 1 hectare

$=1 \times 10000 / 0.3=33333.3 \mathrm{~m}$

Time to be taken by the machine to move $33333.3 \mathrm{~m}$

$=33333.3 / 0.76=43859.6 \mathrm{~s}=12.18$ hours

Field capacity $=1 / 12.18=0.082$ hectare $/$ hour.

This paper deals with the Design, Development and Performance Evaluation of the Manually Controlled Rotary type paddy cutter with the knapsack sprayer power utilization with the following objectives

To design the rotary cutter for the paddy harvester.

To design the Transmission system for the Cutting system.

To test the overall efficiency of the machine.

To evaluates the field capacity of the machine.

The power operated and manually controlled paddy harvester which is given by knapsack mist blower engine and can be controlled manually has been developed. The power source had been kept at 4800 RPM to give 3000 RPM at the cutter with the overall speed transmission efficiency of $75 \%$.

The transmission system has been designed to give a speed reduction of 1.2 by providing bevel gear system. From the designed calculations and dimensions of the machine, it has been calculated the theoretical field capacity as $0.08 \mathrm{ha} / \mathrm{h}$ with a width of cut of 30 $\mathrm{cm}$.

\section{References}

Akritidis C B 1974. The mechanical characteristics of maize stalks in relation to the characteristics of cutting blade. Journal of Agricultural Engineering Research (19):1-5

Bal A S, Sharma V K and Shukla A N 1989. Effect of operational parameters on the performance of basecutter of sugarcane harvester. Journal of Agricultural Engineering Research 26(1):11 - 18

Banno T and Ogowa T 1979. Studies on the cutting energy of a rotary mower. Journal of society of Agricultural machines, Japan.404 (4): 517 - 519 
Chancellor W J 1958. Energy requirements for cutting forage crops. Agricultural Engineering Today (39): 633 - 636

Chattopadhyay P S and Jai Singh 1990. Development and Evaluation of Rotary disc mower for harvesting of forage crops. Agricultural engineering today 14 (1 \&2): 32-40.

Chattopadhyay P S and Ponday K P 1992. Estimation of design parameters of rotary mower through mathematical modeling of impact cutting. Journal of the Institution of Engineers (India), Agricultural Engineering Division 73(2): $56-59$
Claar P Krutz G and Thompson L 1984. Design of agricultural Machinery. John Wiley \& Sons, Newyork.

Datta R K and Tewari V K 1985. Grip strength and Physiological parameters. Proceedings onsilver jubilee Convention ISAE 1(2): 154 -158

Gite L P and Yadav B G 1985. Anthropometric data for Farm Equipment Design Proceedings on Silver Jubilee Convention, ISAE 1(2): $148-153$

Majumdar M R 1968. Development of a high capacity stalk cutter. Agricultural Engineering today 49: 378 - 382

\section{How to cite this article:}

Ravindra Raju, R., P. Shankar Prasad and Rayan Rao, V. 2017. Design, Development and Performance Evaluation of the Manually Controlled Rotary Type Paddy Cutter with the Knapsack Sprayer Power Utilized. Int.J.Curr.Microbiol.App.Sci. 6(11): 2187-2195. doi: https://doi.org/10.20546/ijcmas.2017.611.258 